\title{
Sustainability Transitions: An Investigation of the Conditions under Which Corporations Are Likely To Reshape Their Practices to Reverse Environmental Degradation
}

\author{
Samantha Petersen (Corresponding author) \\ Law Faculty, University of Cape Town, Rondebosch, 7700, South Africa \\ Tel: 27-732-378-185Ｅ-mail: spetersen@wwf.org.za
}

Clifford Shearing and Deon Nel

Worldwide Fund for Nature (WWF- South Africa), 1 Mariendahl Lane

Newlands, 7700, South Africa

Received: November 25, 2014 Accepted: December 8, 2014

doi:10.5296/emsd.v4i1.6673 URL: http://dx.doi.org/10.5296/emsd.v4i1.6673

\begin{abstract}
Increasing levels of the unsustainable use of natural resources have been widely reported. In this paper we argue that engaging private sector corporations to address environmental risks is crucial to solving many of the key environmental challenges humans face. We investigate the enabling conditions under which private sector corporates act to reshape their business. To explore the nature of these enabling conditions we build on conceptual framing drawn from organizational theory and apply this framing to a case study of the South African food and beverage sector. This paper considers the role of awareness in bringing about the changes required, the motivation of those engaged with the key issues, pathways for change and explores the role of rewards. It further investigates the relationship between these four variables (awareness, motivation, pathway and reward) and describes a set of design principles to inform initiatives to bring about change in this context.
\end{abstract}

Keywords: Business, Sustainability, Organisational Transitions, Behavioural Change, Case Study. 


\section{Introduction}

Concerning reports of the state of the planet and natural resources have become increasingly familiar along with a myriad of statistics relating to over-fishing, increasing carbon emissions, deforestation, land degradation and water stress and pollution (Abramovitz, 1996; Butchart et al., 2010; Davidson et al., 2012; Food and Agricultural Organization of the United Nations (FAO), 2010; Kinnard et al., 2011; Larsen et al., 2011; Rogelj et al., 2011). In recent times, many authors have reported increasing levels of extraction of natural resources and waste, while, concurrently, others have described increasing levels of environmental awareness and empathy (Dunlap and Scarce, 1991; Dunlap and Mertig, 1995; Erskine, 1972; McGilchrist, 2009; Rifkin, 2010). Cutting across these different accounts has been an opposition between two world views that adopt very different conceptions of humans and their relationship to earth systems -- one places humans outside of natural systems (Passmore, 1974), while the other conceives of them as integral to, and embedded in, natural systems (Naess, 1973). The first view conceives of conservation as protectionist and concerned with the maintenance of pristine ecosystems. It sees ecosystems as at odds with economic development, which is viewed as destructive of them (Loo, 2007). Conservation initiatives informed by this view have consistently failed to effectively protect the planet's natural resources and ecological services (World Wide Fund for Nature (WWF), 2012; Lynas, 2011). As a consequence, this once self-evident view is today being rapidly replaced by the second world view as the dominant understanding (Fischer et al., 2007; Lowe, 1994). In this second view the maintenance of healthy ecosystems across the globe, and not simply in isolated pristine enclaves, is conceived of as essential for sustaining human well-being. It recognises limits to the goods and services that can be provided by ecological systems. A variety of studies (e.g. Barnosky et al., 2012; Butchart et al., 2010; Lynas, 2011; Rockström et al., 2009; WWF, 2012) have documented that these physical boundaries either have been breached, or will soon be breached, unless humans drastically change their established practices for engaging earth systems. Despite the increasing dominance of this second world view in the academic literature, as yet, humans have done relatively little to effectively reshape the way they engage earth systems - this engagement continues to arise out of, and reflect, the first view. As a consequence, ecological boundaries not only continue to be threatened, but this threat is escalating. This disjuncture raises questions as to how this second world view can become more firmly embedded in society, business and governments in ways that will enable the changes required to reshape human engagement with earth systems.

In considering this question the corporate sector has been identified by some as the 'single most influential group' (Robinson, 2012) to catalyse the shifts required to secure the future of the planet (Rose and Colchester, 2004; Azapagic and Perdan, 2000; Azapagic, 2003; Melville and Ross, 2010). However, many have argued that a capitalist economy, given its very nature, is simply unable to respond effectively to this challenge and that it will require pressure from the outside (Foster et al., 2010). Some authors have furthered questioned whether partnerships between environmental organisations and corporates simply act as a mechanism to legitimise 'business as usual' or may even result in the speeding up of large- scale extraction and degradation of natural resources and ecosystems (Dowling et al., 2004; Igoe et al., 2010; Kelly, 
2012; MacDonald, 2010; Robinson, 2012; Rose and Colchester, 2004). However, there is now a growing body of evidence recognising the positive role business can play in bringing about the changes required to live within the bounds of the planet (e.g. Orlitsky et al., 2003, Porter and Kramer, 2011, Azapagic, 2003).

This study investigates the conditions under which business is likely to re-shape their practises to sustainably engage earth systems by interrogating a number of partnerships between an environmental organisation and the South African food and beverage sector. It outlines key factors critical to enabling the transition; it explores their inter-relationship and proposes a set of design principles key to catalysing the shift. The growing literature on sustainability transitions in business has an overwhelming focus on developed economy contexts (for an overview, see Van den Bergh et al., 2011; Lawhon and Murphy, 2012). The conditions for change may be different in a developing economy context due to the stronger need for development and poverty alleviation (and frequently viewed in opposition to an environmental agenda). Furthermore, this study specifically responds to a call in the literature for studies to consider cases of both more and less successful partnerships as well as partnerships which are at varying stages of progress (Bertels et al., 2010). The variety of cases is likely to provide a more comprehensive list of conditions and more likely to draw out implicit conditions that may otherwise have been missed. Conditions that are not obvious in successful cases may become obvious in less or even unsuccessful cases. The partnerships under consideration are situated in South Africa, a developing world economy, some of which are only just emerging while others are highly evolved and more or less successful. These partnerships fall across a number of sector-specific initiatives: one of these focus on the South African retail sector with a specific interest in seafood sustainability, the second focused on the fishing industry and the third explores the responses of a major beverage company as it recognises and responds to water boundaries. These cases were selected because they provided a good cross section of the above mentioned factors, as well as insights into private sectors with differing levels of interaction with the environment. Both the fishing sector and the beverage company provided excellent cases of two sectors that are directly reliant on functioning ecosystems for their livelihood (e.g. fish or water). The retail sector provided insights into private sector corporates one step removed from the environment by the nature of their supply chains. This variety provided rigor and diversity in this study, which deepened the findings.

\section{Materials and Methods}

In the research, semi-structured interviews and focus groups were used to explore change processes. Twenty-six interviews were conducted (three with academics, nine with private sector corporates, seven with government officials, five with NGOs, one with a consumer) between September and December 2012. Two focus groups were facilitated, one with 6 individuals, mostly academics with a research focus of reconnecting society with the environment, and the other with 11 individuals leading the initiatives from WWF and their corporate partners. The transcribed interviews were used verbatim and coded using coding criteria, which were progressively refined as coding took place, using a reflexive, systematic, iterative process (Layder, 1998). This approach consisted of consistent consultation of theory, reflexively comparing data and iteratively seeking trends to guide the distillation of conditions 
for change.

The partnerships which focus on seafood sustainability are designed to harness the power of the market to incentivise responsible fishing. The guiding idea behind this initiative was that by providing retailers, restaurants and consumers with information about the relative sustainability of their seafood choices will enable them to make choices that promote more sustainable harvesting practices. It particularly focuses on working with retailers to use their purchasing power to promote sustainable harvesting at the supply end of the chain. The intention is to encourage retailers to only source products from harvesters that have demonstrated the sustainability of their harvesting practices through independent assessment by credible certification schemes, or that have committed to time-bound improvement projects. These arrangements are intended first, to reward fisheries that are harvesting responsibly by creating a market advantage and secondly, to incentivise other harvesters who are not yet enjoying these market advantages to improve their practices by embarking on fishery improvement projects. The fisheries case focuses on partnerships between WWF and three of biggest fishing companies in South Africa. The intention of these partnerships is to proactively address some of the key challenges facing the sector.

The third case study focuses on a WWF initiative that recognizes that South Africa is a water stressed country with huge economic development pressures and social challenges. Water availability is a decisive factor that will affect the economic, social and environmental well-being of South Africa over the next decade and beyond as its supply is already precariously limited. In recognition of this WWF has established a partnership with the largest brewery in South Africa to explore how a concept of shared value can be created in order to incentivize the necessary changes required to address water risk issues.

\section{Theory}

This study applies and further develops a conceptual framing developed by Honig et al. (in press) which concluded that three elements are crucial to bringing about pro-environmental behaviour, namely a) an awareness of key issues, b) a motivation to act, and c) a way to act or a pathway.

The work of Honig et al. (in press) draws on concepts from a number of bodies of literature, particularly organizational theory, psychology and pro-environmental behaviour change (Cohen et al., 1972; Cyert and March, 1963; March and Simon, 1958; March, 1991; Simon, 1947, Darnton, I., 2008., Tudor et al., 2008; Osbaldiston and Schott, 2012, Wejnert, 2002). The first term we draw on is that of 'awareness'. Awareness, or 'attention', has long been recognized within organizational theory as a feature of organizations (Cohen et al., 1972; March and Simon, 1958; Simon, 1947). For the purposes of this study the term 'Awareness' refers to the understanding within companies of the state of the ecological systems, or infrastructures, with which their industry engages through their extraction of natural resources and waste practices. It is important to note that our definition of the term 'awareness' is broader than the acquisition of knowledge, but includes a sensibility or frame of reference out of which action emerges (Shearing and Ericson, 1991). 


\section{Ml Macrothink}

The second key concept is that of 'Motivation'. Motivation creates the momentum for action. Both psychological (Greenhalgh 2004) and institutional factors affect motivation (e.g. Bernard 1938; Mahoney, 2005). However, in this context, crucially important is institutional culture, understood here as "the way we do things around here" (Deal and Kennedy, 2000). For the purposes of this study, the term 'Motivation' refers to the drive of companies to change ecologically harmful practices.

Third, is the concept that of 'Pathways' (Merton, 1949). All action requires pathways. Sometimes pathways are available but are not activated because there is not a sufficiently developed motive to drive action (Braithwaite and Drahos, 2001). Alternatively, a corporate may be motivated, but implementation may not be a trivial task (Azapagic, 2003). Within the sustainability arena, many pathways that corporates have adopted have resulted in an "add-on" to business as usual (Porter and Kramer, 2011). There are few management frameworks that outline a generic pathway to corporate sustainability, with a few notable exceptions (e.g. Azapagic, 2003; Hitchock and Willard, 2009). For the purposes of this study the term 'Pathway' refers to a possible course of action that would enable companies to shift their practices towards sustainability.

A fourth concept not considered by Honig et al. (in press) but considered in this study is that of 'Reward' (a positive feedback). Reward refers to benefits and payoffs that either had been realised or were expected to result from actions taken by the company - while this can be seen as an element of motivation (payoffs are often anticipated) we have, in our framing, treated it as a separate element.

This study thus considers these four concepts - awareness, motivation, pathways and rewards. It investigates their role in bringing about social change for sustainability within business and interrogates the interrelationship between these variables. While a number of these terms have been relatively well studied individually or in pairs, (e.g. awareness and motivation (Fisher et al., 2002); motivation and pathways (Thaler and Sunstein, 2008) and payoffs and motivation (Ballard and Ballard, 2005)), we found very little explicit attention across all four variables. This study thus pays particular attention to how these four concepts relate to one another to enable business to contribute to environmental sustainability.

\section{Results}

\subsection{Awareness (A)}

Our respondents, almost to a person, reported that, over the past decade or so, they had become increasingly aware, both very generally and specifically in relation to their industries, of the presence and the importance of ecological infrastructures for the well-being of humans and their industries (Table 1). They typically expressed this as growing background awareness, which had been constituted by many different information sources that ranged from general media accounts to reports directly relevant to their industries. They did however, suggest that this awareness increased exponentially as they personally experienced the effect of environmental change (e.g. reduction in catch or reduced water supply) (Table 1). This finding is supported in the literature (Holley et al, 2012; Kim and Mauborgne, 2003). 


\section{Macrothink}

Environmental Management and Sustainable Development

ISSN 2164-7682

2015, Vol. 4, No. 1

Table 1 . Summary of key findings as they relate to awareness, motivation, pathway and payoff.

\begin{tabular}{|c|c|c|c|}
\hline Awareness & Motivation & Pathway & Reward/Payoff \\
\hline $\begin{array}{l}\text { The importance of understanding or } \\
\text { being aware }\end{array}$ & Marketing advantage & Context specific & Increased profit \\
\hline The value of first-hand experience & $\begin{array}{l}\text { Risk mitigation } \\
\text { *Regulatory risk } \\
\text { *Supply chain } \\
\text { *Brand risk }\end{array}$ & $\begin{array}{l}\text { Typically follows } \\
\text { the following stages: } \\
* \quad \text { Internal } \\
\text { (efficiency driven) } \\
* \text { External (short } \\
\text { supply chains) } \\
* \text { External (longer } \\
\text { supply chains) }\end{array}$ & Decreased risk \\
\hline \multirow[t]{6}{*}{$\begin{array}{l}\text { Understanding the connectedness } \\
\text { between business success and } \\
\text { sustainability }\end{array}$} & $\begin{array}{l}\text { Values and employee } \\
\text { retention }\end{array}$ & & Award/recognition \\
\hline & $\begin{array}{l}\text { Moral/ethical } \\
\text { imperative/social licence to } \\
\text { operate }\end{array}$ & & Customer loyalty \\
\hline & Credibility & & Staff loyalty \\
\hline & Investor & & Innovation \\
\hline & First-mover advantage & & \\
\hline & Increased profits & & \\
\hline
\end{tabular}

Furthermore, while respondents were aware of the views of sceptics they all reported that they recognized that ecological boundaries were threatened and that this had implications for the viability of their industries. They also indicated that they were aware of the fact that their industry's engagement with these systems was impacting them. While our respondents reported that their growing awareness had been punctuated by significant events they did not report a single epiphany, a 'road to Damascus' event that had radically shifted their views. Rather they indicated that their awareness had shifted as a consequence of a host of much smaller events. This shifting awareness had enabled an openness to considering new ways of engaging ecological systems both as individuals and with respect to their businesses.

Awareness, as this study and other research suggests (Holley et al., 2012; Shearing and Ericson, 1991), can be viewed as having two features - knowledge, a cognitive understanding, and sensibility, a way of being in the world that emerges from a particular framing. Our respondents reported that, while a shifting awareness opened up new conceptual spaces and with these new possibilities for action, this alone did not shift their actions. This finding is consistent with a 
number of studies that conclude that increasing knowledge through education alone does not lead to a change in behaviour (Kellert, 1990; Schultz, 2011). This is further supported by Heberlein (2012) who describes the knowledge-deficit model, or cognitive fix, which demonstrates that attitudes have little to do with behaviour. In the cases under consideration, we conclude that, for action to take place, awareness had to be aligned with corporate incentives, for example, individual and division scorecards. What our findings suggest is that awareness tends to begin with knowledge, but may then transition to include a sensibility that was redefining ways of being, which facilitated action. As highlighted above, awareness is most likely to transition into sensibility and contribute to motivation when the consequences of the issues are experienced first-hand by the business itself (e.g. reduction in supply) (see Table 1).

\subsection{Motivation (M)}

A number of factors motivated actors in this study. Risk mitigation was cited most frequently by interviewees including for example supply chain, political and regulatory risk. Related to this was the motivation to partner with their peers or the need to partner with an independent organisation, like an environmental NGO, to gain credibility for their concerns or activities. Other motivations include branding (including profiling or positioning their brand as 'caring for the environment'), increased staff retention, a moral or ethical imperative (some went as far as to refer to the need to gain a 'licence to operate'), while other interviewees were motivated by investor requirements, or to gain a 'first-mover' advantage, but overall the majority of motivations were linked to increased profits or market access in some way or another (Table 1).

A key finding was that the source of motivation is likely to change over time. This may be related to an increase in the understanding of the interconnectedness of environmental issues and human well-being as time goes on. Corporates in the early stages of their 'sustainability journey' typically were motivated by extrinsic motivations, while corporates further along the journey had begun to incorporate intrinsic and extrinsic sources of motivation. Aligning intrinsic and extrinsic sources of motivation, our respondents suggested, was a condition for corporate action.

While awareness alone might on occasion translate into a sufficient motive for action at the individual level, this, our respondents reported, was not sufficient to provide grounds for action that was endorsed at the level of corporate strategy. At a corporate level, awareness served to open spaces for action, but alone was not sufficient to drive action, except perhaps within limited corporate enclaves controlled by 'green champions'. Such action depended upon the presence of a champion within these arenas and were typically not sustained or scaled beyond these areas without top-down corporate buy in.

\subsection{Pathway $(P)$}

Pathways take on many different forms and are typically very context specific. An example, of a NGO-facilitated and managed pathway is the SASSI colour rating of seafood on a traffic light system, which provides a clear and simple pathway for seafood consumers and retailers to make more informed and sustainable choices that enables collective action. 
Our respondents reported that while pathways may be available, they are not always acted upon due to insufficient motivation. It took a corporate crisis of some sort to mobilize support for action through an already established pathway (Table 1). A good example of this comes from the Southern African Sustainable Seafood Institute (SASSI) Retail Participation Scheme: a particular retailer was not motivated to join the programme and only paid superficial attention to the issue of seafood sustainability until a consumer raised the alarm bells (retailer was selling unsustainable seafood) through social media. This quickly gained momentum and was picked up by mainstream media. Almost overnight the issue became a brand risk crises for the company. The result was that the retailer became motivated (by brand risk) and turned to SASSI to provide a pathway to address the issue. These crises catapulted the issue of sustainability to become a top priority and saw the retailer leapfrog other SASSI retail participants who had been in the programme for a number of years, but had not experienced these sorts of crises.

A key finding of this study was that companies addressing issues of sustainability had relatively consistently moved through three phases (Figure 1, Table 1). In the first phase of such a process an integration of sustainability concerns and established corporate objectives finds expression through pathways that are expected to increase efficiencies that will have profitability payoffs (e.g. reducing energy usage, waste and recycling, and improved water use efficiencies). What enables action is a pathway that promises immediate and significant savings - when this is the case it tends to be easy to make a business case for action. Often this alignment of motives is identified, and driven, by green champions within the company who are on the lookout for ways of prompting corporate action. A word of caution here: in some cases corporations 'got stuck' in this phase and found it difficult to transition into the next phase. This is an area that requires further investigation.

A second phase resulted in a deeper transformation through a broader sphere of influence. In this case, this was predominately expressed through an engagement with supply chains (but the phenomenon was not constrained to supply chains) by enrolling their suppliers, our respondents reported, through the mobilisation of influence exerted through well established relationships e.g. a retailer that has a history of procuring seafood directly from a fishing company. This phase typically focused on short supply chains where the risk was most evident (e.g. through reduced supply). The third phase, which only very few corporates interviewed $(n=2)$ had started to understand and initiate, was collective action where the corporate engages across their sphere of influence, including longer supply chains, network of partners (including government, regulators) and policy (Figure 1). In this phase, corporations drove a more comprehensive change across the landscape/seascape over which they believe they have influence. The corporations under review in this research only sought to move beyond close connections within a supply chain when evidence had accumulated of the potential for building collaborative responses. This phase draws upon pathways that emerge as action is taken in phases 1 and 2. 


\section{Al Macrothink}

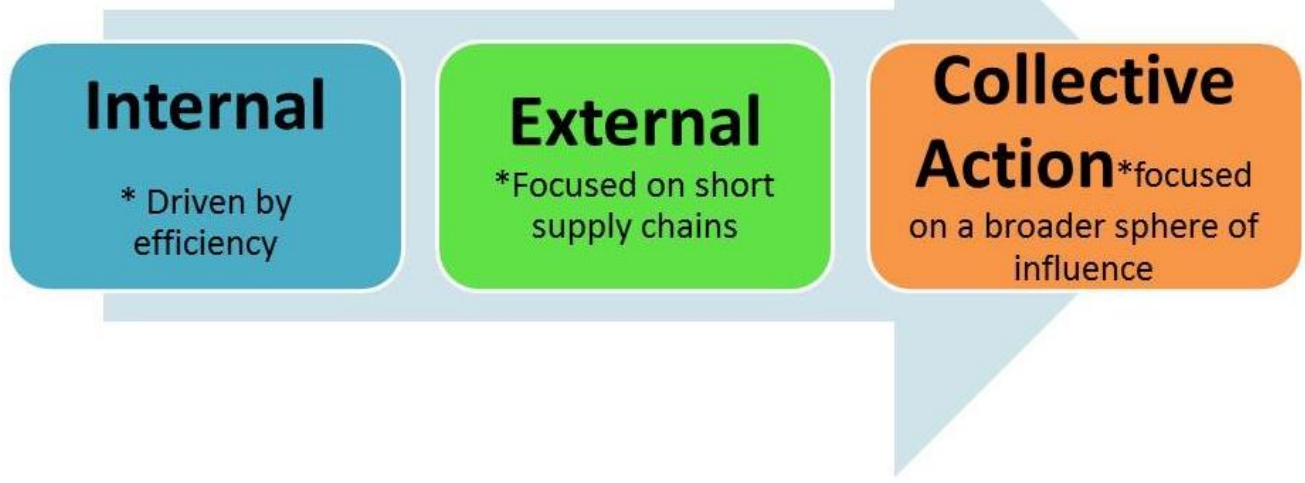

Figure 1. A typical pathway undertaken by a private sector corporate, moving from addressing 1) internal issues (driven by efficiency) to 2) external issues through their supply chain and/or business partners to 3 ) taking collective action across their supply chain and network of

partners.

\subsection{Reward $(R)$}

Reward refers to the benefits that companies receive, which they attribute to the actions they were motivated to take and that their pathways enabled. For example, a 'reward' or 'pay off' may recognise particular behaviour through show-casing an outcome, awarding an individual for a particular action, or demonstrates the value an intervention can offer the business, such as increased profits, growth into a new area/new clients or reduced risk (see Table 1). Other rewards described by interviewees included staff and customer loyalty, and innovation (Table $1)$.

These rewards may, or may not, have been anticipated by companies as part of their decisionmaking processes. They may, for example, have sought to achieve better cost-to-income ratios by developing greater efficiencies, which incidentally would have beneficial consequences for the delivery of ecological services. Similarly, the company may, through their actions, engage in less damaging extraction practices. In these and similar examples, perceived pay off will tend to work to maintain the companies' motivation to continue to act in environmentally friendly ways.

\subsection{Change: Linear, Cyclic or Stepped?}

The elements of AMPR sometimes operate in a fashion as the acronym suggests. When this happens, awareness through a change in sensibility reinforces a particular motivation and this motivation in turn provides the impetus to act (pathway), which, if successful, will in their turn translate into a payoff (A->M->P->R). This may well create a 'virtuous cycle' in which a cascade of 'virtuous' actions ensue (See Figure 2 below). For example, an initially superficial awareness of an environmental concern, a motivation (for example, to reduce costs) that in turn leads to a discovery of a pathway (that does indeed reduce costs). This, in our view, is why 
many private sector corporates get trapped in phase 1 (described above), because this frequently provides a very simple feedback mechanism on efficiency improvement. However, through action, a deepening awareness may occur, which in turn may enhance motivation, stimulate a more intense search for pathways, which increase reward/payoffs and so on.

While sequential AMPR processes do indeed occur, our findings indicate that change frequently did not take place in this fashion. The AMPR elements can, and do, combine in different sequences depending on the specific content. For example, the discovery of a pathway that promotes efficiencies may stimulate the development of motivations that prompt the use of this pathway and the experience of rewards from this may lead to an enhanced awareness (P->M->R->A). Or in another context the motivation may be uncoupled with environmental awareness, as in the case of the retailer who responded to a brand risk as a result of consumer pressure, but had little understanding of the real issue. This motivation leads to engagement in a collaborative mechanism, such as the SASSI retail participation scheme, which in turn increases the awareness of the business or individual involved (M->P->A->R).

A key finding of this study was that change was frequently punctuated by periods of no change or by periods of rapid cascading change. What our cases suggest is that what determine both periods of little or no change and periods of rapid change is reward/payoffs. Where rewards are perceived this may well catalyse more change; where payoffs are not perceived an initiative is likely to flounder. This suggests, as we have already noted, that initiatives that are initially motivated by intrinsic values are likely to flounder at scale if they are not supported by extrinsic rewards. Similarly, initiatives that are often championed by people motivated by intrinsic values will be more likely to succeed and be taken to scale if they are catalysed by rewards such as increased profits, growth into new areas, a reduction of worrying risks and so on (see Table 1). Rewards are important to invoke sustained and deepened responses over time. The challenge with complex sustainability issues is that the rewards are dislocated from the cost in time and space, resulting in long lags between the cost incurred and the reward, or the reward is felt in another part of the system to where the cost is incurred. Our finding thus highlights the need to innovate around rewards, making the links between cost and benefit explicit wherever possible.

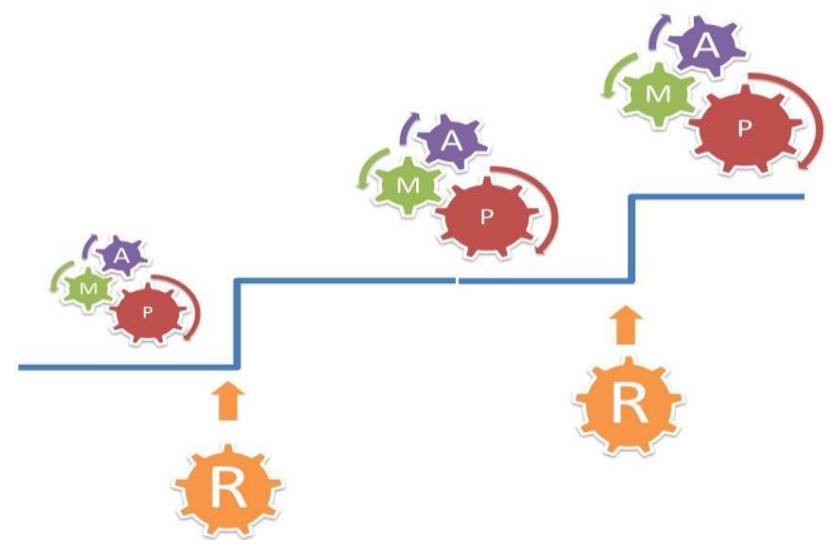

Figure 2. Change over time increases in a stepwise fashion punctuated by moments when the payoff becomes clear (Awareness (A), Motivation (M), Pathway (P) and R (payoff/reward)). 


\subsection{Positioning or Transitioning}

These findings suggest that companies undergo a shift from a stance we refer to as 'positioning' (early stages of sustainability journey) to one of 'transitioning', where they shift core features of the way they do business so that their businesses becomes more sustainable, when payoffs reinforce their initial motivations. 'Positioning', in this understanding is characterized by a superficial level of motivation that is not translated into a robust motivation. This may occur, for example, where the motivation is simply a brand risk event, such as a consumer complaint that captures some media attention. In such a scenario the process may well be led by the marketing department and draw upon corporate social investment budgets. When this happens, environmental degradation is likely to be regarded as external to a company's business interests - namely, as an externality. A 'positioning' phase is characterized by a lack of interest in working collaboratively with competitors and a choice of 'pathways' that are used to create a market advantage for the company.

However, the deployment of an effective pathway that provides ecological payoffs that are perceived to have industry-wide advantages may flip a company into a profoundly different state, namely 'transitioning'. This state is characterized by a deeper understanding of the links between sustainability and business success. It is motivated by supply chain or core business risk, is typically led by, or at least enjoys the active engagement of, procurement and/or other core business employees. In this phase, collaboration with competitors tends to shift as now there is an understanding that the risk is shared, that the job at hand cannot be achieved alone, that the most efficient way to deal with perceived ecological risks is to pool resources. A key feature of this stage is that the sustainability of a business is perceived to be dependent on risks being dealt with in a systemic manner across an industry. At this stage, there is recognition of the value of companies working together. Indeed, some respondents argued that collaboration itself could constitute a new competitive edge for businesses that recognize the shared value inherent in a shared resource.

\subsubsection{Catalysing the Shift}

The study identified the following design principles as pivotal factors in moving the business from a state of 'positioning' to that of 'transitioning':

1. First-hand experience of environmental disaster or impending disaster: This greatly increased the level of awareness and provided motivation for action. An example are the fishing companies participating in the (Responsible Fisheries Alliance (RFA)) who were motivated to change their behaviour to 'custodian harvesters' because they started to experience first-hand that their actions were driving fish stocks to levels which limited their commercial value. This finding is supported in the literature (Kim and Mauborgne, 2003).

2. A business case: There is a need for a clear business case that coherently articulates the case for the proposed intervention (motivation). The development of a business case provides an opportunity to build and deepen the understanding of the key environmental issues and to create explicit links with established objectives of the business. A sound business case establishes a link between the interventions, which 
may initially be motivated by champions who are driven by intrinsic values, and anticipated payoffs associated with consequences, such as increase in income, growth into a new area or risk reduction (e.g. operational, supply chain, regulatory, reputational and financial risks) and other extrinsic values. Furthermore, a sound business case that draws attention to anticipated payoffs that relate to a company's extrinsic values is also likely to resonate with company strategic decision makers.

3. Publically communicated sustainability objectives: This action enrols the public to hold the entity, making sustainability objectives, accountable. It is also important to note that the process of determining the objectives is as important as the outcome. A key finding of this study revealed that when commitments were made externally, a company's brand and hence integrity is put on the line if they do not meet the commitment and hence typically requires sign off by high level decision. This provides the opportunity to a) increase the understanding and awareness of environmental issues to high-level decision makers, b) move the conversation from one between sustainability and marketing staff to sustainability and chief executive staff, c) grapple more deeply with the implications of proposed actions for their business, including grappling with the practicality of proposed actions, which frequently results in refinement and improved probability of success, and d) broader uptake of sustainability strategies within the company (compared to being seen as an add-on and not core to their business).

4. Incentives: This includes personal and company-wide incentives that structure payoffs in ways intended to motivate individuals to find and adopt pathways for change, for example, the inclusion of sustainability objectives into company score cards and individual Key Performance Areas. This inclusion provides increased awareness of the issues, provides a mechanism for developing shared goals, links them to achieving business success and provides a motivation to contribute to delivering agreed upon objectives. Some interviewees noted that these benefits were compromised when incentives were competing. An example of this is when one business unit is incentivised in a manner that contradicts the incentives of another business unit.

5. Demonstration projects: There are three main reasons to undertake demonstration projects. First, they can be useful to demonstrate that it is in fact possible to tackle a particular issue, and secondly, such projects can demonstrate the value a particular project or intervention may have to their business. Given this, our findings suggest that demonstration projects are useful in prompting action when they focus on topics the company can relate to and demonstrate that it is 'do-able'. These linkages are most likely to be recognised when the results are tangible and clearly linked to a company's business strategy. Third, demonstration projects provide company staff and environmental groups with an opportunity to 'get to know each other' and build trust.

6. Recognition/reward: There were a number of examples provided by interviewees that illustrate the importance of being recognized or rewarded for taking action - extrinsic payoffs at an individual level. This was sometimes in the form of an award or by seeing results. An example of this is provided by a seafood consumer who approached 


\section{MInstitute Machin $_{\text {Int }}$}

a seafood retailer to request that they remove a red-listed species from their shelves. When he was successful he was motivated to take on other issues.

7. The importance of a champion: As with most things in life, action is unlikely unless driven by someone. The findings of this study indicate the importance of champions to initiate, co-ordinate and drive implementation.

8. Funding and sufficient capacity: Our findings confirm that sustainable change seldom occurs, except over very short time frames when champions may redirect resources temporarily, if company resources are not allocated to support these change over the medium to longer term - in established companies this typically means a 5 to 10 year time horizon. Enacting pathways requires resource commitments from core budgets.

9. Full accounting/reporting: The results of this study suggest that although reporting is useful to raise awareness of environmental issue and provide a motivation to act, it is not sufficient on its own. In many cases, interviewees reported that the exercise was undertaken by external consultants and frequently results in a 'tick box' exercise.

\section{Discussion and Conclusion}

These cases build our understanding of the behaviour change required, in particular the conditions under which the private corporate sector is likely to reshape their behaviour to sustainably engage earth systems. This study concludes that four factors are critical for meaningful corporate action towards sustainability, namely, awareness, motivation, pathway and reward. Although this finding is consistent with other related research, it provides a novel and comprehensive over-arching framework to review and guide sustainability transitions in business. In an extensive review of the literature on business-driven social change, Stephan et al., 2013 (building on a framework proposed by Michie et al., 2011) propose that motivation, capability and opportunity are the three key elements to drive social change by corporates. Our study builds on this, most notably by identifying that awareness (including a framing that sees business success linked to ecological well-being) was foundational to a full transition to sustainability and thus not simply a contributor to motivation as suggested by Stephan et al. (2013). Furthermore, we consider capability and opportunity as elements of 'pathway', but the cases reviewed in the current study highlight that pathway is not limited to these two elements, but rather a number of factors key to facilitating action. We argue that while all four factors are important, rewards/payoffs are critical to ensuring on-going action.

The AMPR model may be viewed as a behaviour change model. The role of information in driving changed behaviour is well documented, however, it is widely accepted that information alone is insufficient to lead to action (e.g Heberlein, 2012; Kellert, 1990; Kolmuss and Agyeman, 2002; Schultz, 2011). Kolmuss and Agyeman (2002) describe a linear model whereby the presence of environmental knowledge will lead to an environmental attitude and then result in the desired pro-environmental behaviour. Our model builds on this by suggesting that a clear motivation is required to translate knowledge or awareness into a desire to act, but that action will only ultimately take place if there is a way to act or a pathway. This is likely to only continue if there is a payoff e.g. a reward, increased profits, decreased risk etc. Barriers between environmental concern and action include individuality (e.g. laziness, lack of interest, etc.), responsibility (e.g. don't own property) and 
practicality (e.g. lack of time, funding, information, etc.) (Darnton, 2008). The Theory of Reasoned Action (TRA) states that one's beliefs about behavioural outcomes and one's evaluation of those outcomes determine one's attitudes to the behaviour (Ajzen, 1991). This supports our finding that demonstration projects are important. These help to increase one's belief and hence influence attitude towards further projects.

Following on, despite the consistent and highlighted recognition of the need for society (especially key audiences such a business) to reframe to a worldview that sees the connection between human well-being and ecosystem health, there is surprisingly little understanding and explicit theory to aid practitioners to bring this about. The role and importance of shifting mind-sets or paradigms or the power to transcend them in systems transitions has been clearly highlighted by a number of leading authors, including Meadows (1999) and Dostal (2005).

Furthermore, this study reveals that, in most cases, sustainability initiatives between NGOs and business mostly attempt to influence the decision-making nexus by demonstrating extrinsic rewards for acting in an ecologically sustainable manner. While this has demonstrated some merit it is also argued that this alone is unlikely to sustain motivation over time. For example de Groot and Steg (2009) argue that campaigns designed to persuade key players by providing arguments based on egoistic considerations rather than altruistic or biospheric considerations, frequently fail to promote sustainable behaviour because they are designed to motivate egoistic considerations only. By doing so, it is likely that egoistic values are being prioritized, while altruistic and biospheric values are perceived as less important in that context. De Groot and Steg (2009) go on to highlight the importance of including information to support the egoistic (including extrinsic payoffs) and moralisation in campaigns. This further supports the need for business to ultimately reframe to a world view that sees the connection between human well-being and ecosystem health. Currently, the decision-making nexus of most corporations is very stable and focused on short-term benefits. This requires interventions to bring social and environmental externalities into their decision making. We argue that only when taking these into account is seen as being essential for the viability of the company will they act to take meaningful action. Action that will actually change the way we engage earth systems. This paper argues that the pivot is the decision-making nexus and that the payoff is key to reinforce, shift and deepen the motivation. There is a key role for NGOs to play here in making payoffs, which would typically be implicit, explicit. In many cases there are pathways for change, but these are not adopted by the business in a meaningful manner because the business is not sufficiently motivated to do so, nor does it operate out of an awareness or framing that sees the connections between business success and ecosystem health.

A further important factor described in the literature is agency, which can be described simply as having the means to take 'meaningful action' or have the 'power to act' (Ballard and Ballard, 2005; Giddens, 1984). Ballard and Ballard (2005) and Bandura (1991) argue that in most cases agency is acquired through personal experience, which is consistent with the findings of this study that behavioural change was most likely to occur when the effects of environmental issues were experienced personally and when individuals felt they had the capacity to act. Partnerships can provide a pathway for agency (Ballard and Ballard, 2005). If the behaviour is deemed impossible it will not be undertaken, despite motivation being present. Agency 
requires appropriate skills and adequate incentives to be in place. In the context of the model proposed here, we would call this 'pathway' and 'payoff'. Fisher et al. (2002) describe an Information-Motivation-Behaviour (IMB) skills model, which is commonly applied to preventive health behaviours. This models states that those with high levels of information, motivation and behavioural skills will undertake preventive health behaviour. Therefore IMB interventions target knowledge, attitudes, agency and behavioural skills to bring about change in this context. The AMPR model builds on this by going beyond knowledge to the importance of awareness, grouping attitudes and agency as motivation and identifying that there is a need for a pathway that requires the appropriate skills, but suggests that skills alone will not be sufficient.

A limitation of this research is that it places a strong focus on behaviour change with limited attention to the 'non-human' systems, such as IT systems, human resource management, etc., which have been well documented to play a key role in driving corporate behaviour (Powell and Dent-Micallef, 1997; Melville and Ross, 2010). It has been argued that humans are frequently 'slaves to these systems' rather than the other way round and that an initiative aimed at transforming business towards sustainability is better placed focusing on changing these systems than focusing on human behaviour change. However, we argue that on deeper reflection, this is in fact consistent with the AMPR model. We argue that for a private sector corporate transition towards ecological sustainability, key or pivotal individuals in the business need to shift their worldview and motives towards seeing the connection between long-term business and healthy ecosystems and that changing the hard systems provides a key pathway for widespread implementation within their business. This in turn is likely to influence the ethos of others in the business, building on the notion that practise drives culture rather than the other way round (Hofstede, 1994).

However, critical to success is the need to better understand potential 'traps'. This study describes an efficiency trap where the private sector becomes trapped because the feedback mechanism is simple and superficial. This finding is supported by the concept of the Jevons paradox (Blake, 2008), which argues that efficiency alone will not ultimately protect ecological systems. This research argues that key to unlocking this are rewards and payoffs that make the links clear and aid in the process of shifting the worldview to one which sees the individual and their business embedded in the natural world.

Furthermore, our analysis has filled a key gap in the literature. Two conclusions that refine current understanding are, first, that it appears to be more difficult for corporates, within developing economies than those within developed contexts, to reframe to a state that sees the connection between human well-being and environmental well-being and, second, as a consequence, motivation becomes more difficult to shift. This may be because of the dominance of the need for job creation and poverty alleviation in the developing world, which is frequently perceived as being in conflict with the environmental agenda even though we argue that this is not the case. These differences are useful as they help to improve our collective understanding of how to enable business to reshape their practises to bring about a sustainable future. 
In conclusion, the AMPR model provides a useful framework for designing meaningful public-private partnerships and can aid practitioners to improve the likelihood of success by incorporating the critical success factors described in this paper into project implementation plans.

\section{Acknowledgement}

This work is based on research supported in part by the National Research Foundation of South Africa. The grant holder acknowledges that opinions, findings and conclusions or recommendations expressed in any publication generated by the NRF-supported research are that of the authors, and that the NRF accepts no liability whatsoever in this regard. The authors would also like to acknowledge and thank all the interviewees for giving up their time and sharing so openly in our discussions.

\section{References}

Abramovitz, J. N. (1996). Imperiled waters, impoverished future: the decline of freshwater ecosystems. Worldwatch Paper 128. Washington DC: Worldwatch Institute.

Ajzen, I. (1991). The theory of planned behaviour. Organisational behaviour and human decision processes, 50, 179-211.

Azapagic, A. (2003). Systems approach to corporate sustainability: A General Management Framework. Chemical Engineering Research \& Design (Trans IChemE), 81, 303-316. http://dx.doi.org/10.1205/095758203770224342

Azapagic, A. \& Perdan, S. (2000). Indicators of sustainable development for industry: a general framework. Process Safety and Environmental Protection 78(4), 243-261. http://dx.doi.org/10.1205/095758200530763

Ballard, D., \& Ballard, S. (2005). Warm hearts and cool heads: the leadership potential for climate change champions. An Alexander Ballard \& Associates report for Hampshire County Council, UK. [Online] Available: http://www.espace-project.org/part1/publications/reading/hccChampsVol1.pdf (December 18, 2014)

Bandura, A. (1991) Social cognitive theory of self-regulation. Organisational behaviour and human decision processes, 50(2), 248-287. http://dx.doi.org/10.1016/0749-5978(91)90022-L

Barnosky, A. D., Hadly, E. A., Bascompte, J., Berlow, E. L., Brown, J. H., Fortelius, M., Getz, W. M., Harte, J., Hastings, A., Marquet, P. A., Martinez, N. D., Mooers, A., Roopnarine, P., Vermeij, G., Williams, J. W., Gillespie, R., Kitzes, J., Marshall, C., Matzke, N., Mindell, D. P., Revilla, E. \& Smith, A. B. (2012). Approaching a state shift in Earth's biosphere. Nature, 486, 52-58. http://dx.doi.org/10.1038/nature11018

Bernard, C. I. (1938). Functions of the executive. Cambridge, MA: Harvard University Press.

Bertels, S., Papania, L. \& Papania, D. (2010). Embedding sustainability in organizational culture. A systematic review of the body of knowledge. London, Canada: Network for Business 
Sustainability.

Blake, A. (2008). Historical Overview of the Jevons Paradox in the Literature. In J.M. Polimeni, K. Mayumi \& M. Giampietro (Eds.), The Jevons Paradox and the Myth of Resource Efficiency Improvements (pp. 7-78). London: Earthscan.

Braithwaite, J., \& Drahos, P. (2001). The Globalisation of Regulation. The Journal of Political Philosophy, 9, 103-128. http://dx.doi.org/10.1111/1467-9760.00120

Butchart, S. H., Walpole, M., Collen, B., van Strien, A., Scharlemann, J. P., Almond, R. E., Baillie, J. E., Bomhard, B., Brown, C., Bruno, J., Carpenter, K. E., Carr, G. M., Chanson, J., Chenery, A. M., Csirke, J., Davidson, N. C., Dentener, F., Foster, M., Lamarque, J. F., Leverington, F., Loh, J., McGeoch, M. A., McRae, L., Minasyan, A., Hernandez, M. M., Oldfield, T. E., Pauly, D., Quadar, S., Revenga, C., Sauer, J. R., Skolnik, B., Spear, D., Stanwell-smith, D., Stuart, S. N., Symes, A., Tierney, M., Tyrrell, T. D., Vie, J. C., \& Watson, R. (2010). Global biodiversity: indicators of recent declines. Science, 328(5982), 1164-1168. http://dx.doi.org/10.1126/science.1187512

Cohen, M. D., March, J. G., \& Olsen, J. P. (1972). A garbage can model of organizational choice. Administrative Science Quarterly, 17, 1-25.

Cyert, R. M., \& March, J. G. (1963). A behavioral theory of the firm. Englewood Cliffs, NJ: Prentice-Hall.

Darnton, I. (2008). An overview of behaviour change models and their uses. An unpublished Report by I. Darnton, Centre for Sustainable Development, University of Westminster, for the UK Government Social Research. [Online] Available: http://www.civilservice.gov.uk/wp-content/uploads/2011/09/Behaviour_change_reference_re port_tcm6-9697.pdf (December 18, 2014)

Davidson, E. A., de Araujo, A. C., Artaxo, P., Blach, J. K., Brown, I. F., Coe, M. T., deFries, R. S., Keller, M., Longo, M., Munger, J. W., Schroeder, W., Soares-Filho, B. S., Souza, C. M. Jr. \& Wofsy, S. C. (2012). The Amazon basin in transition. Nature, 481(7381), 321-328. http://dx.doi.org/10.1038/nature10717

De Groot, J. I. M., \& Steg, L. (2009). Mean or green: which values can promote stable pro-environmental behavior? Conservation Letters, 2, 61-66. http://dx.doi.org/10.1111/j.1755-263X.2009.00048.x

Deal, T. E., \& Kennedy, A. A. (2000). Corporate Cultures: The Rites and Rituals of Corporate Life. Cambridge, MA: Perseus Books.

Dostal, E. (2005). Biomatrix: A Systems Approach to Organisational and Societal Change $\left(3^{\text {rd }}\right.$ ed.). Cape Town: Imaging Data Solutions.

Dowling, B., Powell, M., \& Glendinning, C. (2004). Conceptualising successful partnerships. Health and social case in the community, 12, 309-317. http://dx.doi.org/10.1111/j.1365-2524.2004.00500.x 


\section{1) Macrothink}

Environmental Management and Sustainable Development

ISSN 2164-7682

2015, Vol. 4, No. 1

Dunlap, R., \& Mertig, A. (1995). Global concern for the environment: is affluence a prerequisite? Journal of Social Issues, $51, \quad 121-138$. http://dx.doi.org/10.1111/j.1540-4560.1995.tb01351.x

Dunlap, R., \& Scarce, R. (1991). The polls-poll trends: environmental problems and protection. Public Opinion Quarterly, 55, 651-672.

Erskine, H. (1972). The polls: pollution and its costs. Public Opinion Quarterly, 36, 120-135.

Food and Agricultural Organization of the United Nations (FAO). (2010). The state of the world fisheries and aquaculture 2010. Rome: FAO.

Fischer, J., Manning, A. D., Steffen, W., Rose, D. B., Daniell, K., Felton, A., Garnett, S., Gilna, B., Heinsohn, R., Lindenmayer, D. B., MacDonald, B., Mills, F., Newell, B., Reid, J., Robin, L., Sherren, K., \& Wade, A. (2007). Mind the sustainability gap. Trends in Ecology and Evolution, 22(12), 621-624. http://dx.doi.org/10.1016/j.tree.2007.08.016

Fisher, J., Fisher, W., Bryan, A., \& Misovich, S. (2002). Information-Motivation- Behavioural skills Model- based HIV risk behaviour change intervention for inner-city high school youth. Health Psychology 21(2), 177-186. http://dx.doi.org/10.1037/0278-6133.21.2.177

Foster, J. B., Clark, B., \& York, R. (2010). The Ecological Rift: Capitalism's War on the Earth. New York: Monthly Review Press.

Giddens, A. (1984). The constitution of society - outline of the theory of structuration. Berkeley and Los Angeles: University of California Press.

Greenhalgh, T. (2004). Diffusion of innovations in service organizations: systematic review

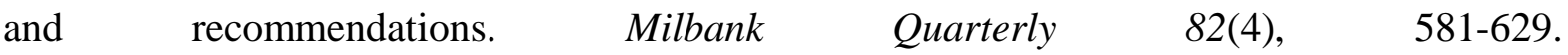
http://dx.doi.org/10.1111/j.0887-378X.2004.00325.x

Heberlein, T. A. (2012). Navigating environmental attitudes. Conservation Biology, 26(4), 583-585. http://dx.doi.org/10.1111/j.1523-1739.2012.01892.x

Hitchcock, D., \& Willard, M. (2009). The business guide to sustainability: Practical strategies and tools for organisations. London: Earthscan.

Hofstede, G. (1994). Cultures and Organisational: Intercultural Co-operation and its Importance for Survival. London: Harper Collins.

Holley, C., Gunningham, N., \& Shearing, C. (2012). The New Environmental Governance. London: Earthscan.

Honig, M., Petersen, S.L., Roux, S., Nel, D. N., Herbenstein, T., \& Shearing, C. (In press). A Conceptual Framework to Enable the Changes Required for a Sustainable Future. Environmental Values. [Online] Available: http://www.whpress.co.uk/EV/EVpapers.html (December, 18, 2014)

Igoe, J., Neves, K., \& Brockington, D. (2010). A spectacular eco-tour around the historic bloc: theorising the convergence of biodiversity conservation and capitalist expansion. Antipode, 42, 
486-512. http://dx.doi.org/10.1111/j.1467-8330.2010.00761.x

Kellert, S. (1990). Public attitudes and beliefs about the wolf and its restoration in Michigan. Madison, WI: HBRS, Inc.

Kelly, C. (2012). Measuring the performance of partnerships: why, what, how, when? Geography Compass, 6(3), 149-162. http://dx.doi.org/10.1111/j.1749-8198.2012.00476.x

Kim, W.C. \& Mauborgne, R. (2003). Tipping Point Leadership. Harvard Business Review, April, 36-47.

Kinnard, C., Zdanowicz, C. M., Fisher, D. A., Isaksson, E., de Vernal, A., \& Thompson, L.G. (2011). Reconstructed changes in Arctic sea ice over the past 1450 years. Nature, 479(7374), 509-512. http://dx.doi.org/10.1038/nature10581

Kolmuss, A., \& Agyeman, J. (2002). Mind the gap: why do people act environmentally and what are the barriers to pro-environmental behavior?. Environmental Education Research, 8(3), 239-260. http://dx.doi.org/10.1080/13504620220145401

Larsen F. W., Londonõ-Murcia, M. C., \& Turner, W. R. (2011). Global priorities for conservation of threatened species, carbon storage and freshwater services; scope for synergy? Conservation Letters, 4(5), 355-363. http://dx.doi.org/10.1111/j.1755-263X.2011.00183.x

Lawhon, M., \& Murphy, J. T. (2012). Socio-technical regimes and sustainability transitions Insights from political ecology. Progress in Human Geography, 36(3), 354-378. http://dx.doi.org/10.1177/0309132511427960

Layder, D. (1998). Sociological Practice: Linking Theory and Social Research. London: SAGE.

Loo, T. (2007). States of Nature: Conserving Canada's Wildlife in the Twentieth Century. Vancouver: University of British Columbia Press.

Lowe, I. (1994). Performance Measurement. Proceedings of the Fenner Conference on the Environment, November 1994. Department of Environment, Sport and Territories, Australian Government. Canberra, Australia.

Lynas, M. (2011). The God Species: How the planet can survive the age of humans. London: Harper Collins.

MacDonald, K.I. (2010). The devil is in the (bio)diversity: private sector "engagement" and the restructuring of biodiversity conservation. Antipode, 42, 513-550. http://dx.doi.org/10.1111/j.1467-8330.2010.00762.x

Mahoney, J.T. (2005). Economic Foundations of Strategy. Thousand Oaks, CA: Sage

March, J. G. (1991). Exploration and exploitation in organizational learning. Organizational Science, 2(1), 71-87. http://dx.doi.org/10.1287/orsc.2.1.71

March, J. G., \& Simon, H. A. (1958). Organizations. New York, London, Sydney: John Wiley $\&$ Sons. 
Mc Gilchrist, I. (2009). The Master and His Emissary: The Divided Brain and the Making of the Western World. New Haven, CT: Yale University Press.

Meadows, D. (1999). Leverage points: places to intervene in a system. Hartland, VT: The Sustainability Institute.

Melville, N. P., \& Ross, S. M. (2010). Information systems innovation for environmental sustainability. Management Information Systems Quarterly, 34(1), 1-21.

Merton, R. (1949). Social Theory and Social Structure. New York: Free Press.

Michie, S., van Stralen, M. M., \& West, R. (2011). The behaviour change wheel: A new method for characterising and designing behaviour change interventions. Implementation Science, 6(1), 42. http://dx.doi.org/10.1186/1748-5908-6-42

Naess, A. (1973). The shallow and the deep, long-range ecology movement. Inquiry, 16, 95-100.

Orlitzky, M., Schmidt, F. L., \& Rynes, S. L. (2003). Corporate social and financial performance: A meta-analysis. Organization Studies 24(3), 403-441. http://dx.doi.org/10.1177/0170840603024003910

Osbaldiston, R. \& Schott, J. P. (2012). Environmental Sustainability and Behavioral Science: Meta-Analysis of Proenvironmental Behavior Experiments. Environment and Behavior, 44(2), 257-299. http://dx.doi.org/10.1177/0013916511402673

Passmore, J. (1974). Man's Responsibility for Nature (2 ${ }^{\text {nd }}$ ed). London: Duckworth.

Porter, M. E. \& Kramer, M. R. (2011). Shared Value. Harvard Business Review, 89(1), 2-17.

Powell, T.C. \& Dent-Micallef, A. (1997). Information technology as competitive advantage: the role of human, business and technology resources. Strategic Management Journal, 18(5), $375-405$.

Rifkin, J. (2010). The Empathic Civilization: The Race to Global Consciousness in a World in Crisis. New York: Jeremy P. Tarcher.

Robinson, J. G. (2012). Common and conflicting interests in the engagements between conservation organizations and corporations. Conservation Biology, 26(6), 967-977. http://dx.doi.org/10.1111/j.1523-1739.2012.01914.x

Rockström, J., Steffen, W., Noone, K., Persson, A., Chapin, F.S., Lambin, E.F., Lenton, T.M., Scheffer, M., Folke, C., Schellnhuber, H.K., Nykvist, B., de Wit, C.A., Hughes, T., van der Leeuw, S., Rodhe, H., Sörlin, S., Snyder, P.K., Costanza, R., Svedin, U., Falkenmark, M., Karlberg, L., Corell, R.W., Fabry, V.J., Hansen, J., Walker, B., Liverman, D., Richardson, K., Crutzen, P., \& Foley, J.A. (2009). A safe operating space for humanity. Nature, 461, 472-475. http://dx.doi.org/10.1038/461472a

Rogelj, J., Hare, W., Lowe, J., van Vuuren, D.P., Riahi, K., Matthews, B., Hanaoka, T., Jiang, K., \& Meinshausen, M. (2011). Emission pathways consistent with a 2 degree C global 
temperature limit. Nature climate change, 1(8), 84-90. http://dx.doi.org/10.1038/nclimate1258

Rose, M., \& Colchester, M. (2004). Green corporate partnerships - are they an essential tool in achieving the conservation mission, or just a ruse for covering up ecological crimes? The Ecologist, July/August, 30-33.

Schultz, P. W. (2011). Conservation means behavior. Conservation Biology, 25, 1080-1083. http://dx.doi.org/10.1111/j.1523-1739.2011.01766.x

Shearing, C. D., \& Ericson, R. V. (1991). Culture as Figurative Action. The British Journal of Sociology, 42(4), 481-506.

Simon, H. A. (1947). Administrative Behavior. New York: Macmillan.

Stephan, U., Patterson M., \& Kelly, C. (2013). Business-driven social change: A systematic review of the evidence. Network for Business Sustainability. [Online] Available: http://nbs.net/wp-content/uploads/NBS-Systematic-Review-Social-Change1.pdf (December $18,2014)$

Thaler, R. H., \& Sunstein, C. R. (2008). Nudge: Improving decisions about health, wealth, and happiness. New Haven, CT: Yale University Press.

Tudor, T.L., Barr, S. W., \& Gilg, A.W. (2008). A Novel Conceptual Framework for Examining Environmental Behavior in Large Organizations: A Case Study of the Cornwall National Health Service (NHS) in the United Kingdom. Environment and Behavior, 40, 426-450. http://dx.doi.org/10.1177/0013916507300664

Van den Bergh, J. C. J. M., Truffer, B., \& Kallis, G. (2011). Environmental innovation and societal transitions: introduction and overview. Environmental Innovation and Societal Transitions, 1(1), 1-23. http://dx.doi.org/10.1016/j.eist.2011.04.010

Wejnert, B. (2002). Integrating models of diffusion of innovations: a conceptual framework. $\begin{array}{llll}\text { Annual Review } & \text { of } & \text { 29ciology, } & \end{array}$ http://dx.doi.org/10.1146/annurev.soc.28.110601.141051

World Wide Fund for Nature (WWF). (2012). Living Planet Report 2012. Gland, Switzerland: WWF International.

\section{Copyright Disclaimer}

Copyright for this article is retained by the author(s), with first publication rights granted to the journal.

This is an open-access article distributed under the terms and conditions of the Creative Commons Attribution license (http://creativecommons.org/licenses/by/3.0/). 